\title{
Variações de coleta e temperatura de secagem no óleo essencial de inflorescências de
}

\section{Hyptis marrubioides}

\author{
Colletion variations and drying temperature in the essential oil inflorescences of Hyptis \\ marrubioides
}

\author{
Variaciones de recogida y temperatura de secado en el aceite esencial de inflorescencias de Hyptis \\ marrubioides
}

\section{Resumo}

Hyptis marrubioides Epling é popularmente conhecida por hortelã-do-campo e faz parte da família Lamiaceae. É uma espécie característica do Cerrado Brasileiro, cujas propriedades medicinais do óleo essencial já foram comprovadas cientificamente. Mediante os vários fatores que influenciam o teor e a composição química do óleo essencial, objetivou-se identificar quais condições de coleta e temperatura de secagem das inflorescências proporcionam maior teor de óleo essencial e possíveis variações químicas da fração volátil. Foi conduzido um experimento em delineamento inteiramente casualizado (DIC), em esquema fatorial. Foram estudadas duas posições de coleta de inflorescências de $H$. marrubioides na planta matriz (apical e mediana) e duas temperaturas de secagem do material vegetal $\left(40\right.$ e $\left.60^{\circ} \mathrm{C}\right)$, totalizando quatro tratamentos, com análises em duplicatas. O óleo essencial foi extraído através de arraste a vapor e posteriormente foi realizada análise química de quatro parcelas experimentais através de Cromatografia Gasosa Acoplada a Espectrometria de Massas (CGEM). Conclui-se que a posição apical das inflorescências de Hyptis marrubioides apresenta maior teor de óleo essencial, especialmente quando submetida à temperatura de secagem de $60^{\circ} \mathrm{C}$. As variações da posição de coleta e temperatura de secagem proporcionaram mudanças quantitativas e qualitativas na análise química do óleo essencial de inflorescências de H. marrubioides.

Palavras-chave: Hortelã-do-campo; Dossel da planta; Secagem; Fração volátil; Constituintes químicos.

\begin{abstract}
Hyptis marrubioides Epling is popularly known as field mint and is part of the Lamiaceae family. It is a characteristic species of the Brazilian Cerrado, whose medicinal properties of essential oil have already been scientifically proven. Through the various factors that influence the content and chemical composition of the essential oil, the objective was to identify which conditions of collection and drying temperature of the inflorescences provide higher essential oil content and possible chemical variations of the volatile fraction. An experiment was carried out in a completely randomized design (DIC), in a factorial scheme. Two collection positions of $H$. marrubioides inflorescences on the parent plant (apical and median) and two drying temperatures of the plant material $\left(40\right.$ and $\left.60^{\circ} \mathrm{C}\right)$ were studied, totaling four treatments, with analyzes in duplicates. The essential oil was extracted by steam drag and subsequently chemical analysis of four experimental plots was carried out using Gas Chromatography Coupled to Mass Spectrometry (GCEM). It is concluded that the apical position of the inflorescences of Hyptis marrubioides has a
\end{abstract}


higher essential oil content, especially when subjected to a drying temperature of $60^{\circ} \mathrm{C}$. Variations in the collection position and drying temperature provided quantitative and qualitative changes in the chemical analysis of the essential oil from $H$. marrubioides inflorescences.

Keywords: Field-mint; Plant canopy; Drying; Volatile fractio; Chemical constituents.

\section{Resumen}

Hyptis marrubioides Epling se conoce popularmente como menta de campo y es parte de la familia Lamiaceae. Es una especie característica del Cerrado brasileño, cuyas propiedades medicinales del aceite esencial ya han sido científicamente probadas. A través de los diversos factores que influyen en el contenido y composición química del aceite esencial, el objetivo fue identificar qué condiciones de recolección y temperatura de secado de las inflorescencias proporcionan mayor contenido de aceite esencial y posibles variaciones químicas de la fracción volátil. Se realizó un experimento en un diseño completamente aleatorizado (DIC), en un esquema factorial. Se estudiaron dos posiciones de recolección de inflorescencias de H. marrubioides en la planta madre (apical y mediana) y dos temperaturas de secado del material vegetal $\left(40\right.$ y $\left.60^{\circ} \mathrm{C}\right)$, totalizando cuatro tratamientos, con análisis por duplicado. El aceite esencial se extrajo mediante arrastre de vapor y posteriormente se realizó el análisis químico de cuatro parcelas experimentales mediante cromatografía de gases acoplada a espectrometría de masas (GCEM). Se concluye que la posición apical de las inflorescencias de Hyptis marrubioides tiene un mayor contenido de aceite esencial, especialmente cuando se somete a una temperatura de secado de $60^{\circ} \mathrm{C}$. Las variaciones en la posición de recolección y la temperatura de secado proporcionaron cambios cuantitativos y cualitativos en el análisis químico del aceite esencial de las inflorescencias de H. marrubioides.

Palabras clave: Menta-del-campo; Dosel de la planta; El secado; Fracción volatile; Componentes químicos.

\section{Introdução}

Hyptis marrubioides Epling é vulgarmente conhecida por hortelã-do-campo. Faz parte da família Lamiaceae, com ocorrências confirmadas no Centro-Oeste (Goiás), Sudeste (Minas Gerais, São Paulo), Sul (Paraná) e domínios fitogeográficos do Cerrado e Mata Atlântica (Harley et al., 2015). Plantas da família Lamiaceae em sua maioria são herbáceas ou arbustivas (Santos et al., 2018).

A família Lamiaceae abriga aproximadamente 300 gêneros e 7.500 espécies. Dentre esses números, 28 gêneros e 350 espécies são encontrados no Brasil, inclusive, o gênero em estudo é nativo do país (Souza \& Lorenzi, 2008). Plantas do gênero Hyptis demonstram metabolismo significativo na produção de óleos essenciais (Batista et al., 2015).

O óleo essencial de Hyptis marrubioides demonstra atividades inseticida, verificada por Mello et al. (2014), no controle de Zabrotes subfasciatus (caruncho do feijão) e antifúngica, averiguado por Silva et al. (2014) no manejo de soja com Phakopsora pachyrhizi (ferrugem asiática). Já o extrato metanólico de H. marrubioides expressa propriedades antioxidantes e anti-AChE, seus compostos fenólicos proporcionam possibilidade de tratamento para enfermidades neurodegenerativas Magalhães, Rios e Dias (2020). Ao pesquisar sobre teor de fenóis totais e flavonoides entre quatro espécies do gênero Hyptis, Povh, Santos e Silva (2012) identificaram maior quantidade de compostos fenólicos na espécie H. marrubioides. Dantas et al. (2021) identificaram em calos H. marrubioides cultivados no escuro a produção dos compostos fenólicos ácido cafeico, ácido clorogênico, ácido rosmarinico e luteolina. Já Rodrigues et al. (2019) ao analisarem em Headspace-CG/MS a fração volátil de H. marrubioides Epl. propagadas in vitro em diferentes concentrações de citocininas, concluíram que os compostos majoritários foram sabineno, $\alpha$-tujona, $\beta$-tujona, $\alpha$-copaeno, $\beta$-cariofileno, $\gamma$-gurjuneno e $\gamma$-himachaleno.

A produção de óleo essencial é afetada por fatores genéticos e ambientais, tais como clima, sazonalidade, temperatura, bem como pela técnica utilizada na colheita e pós-colheita (Morais, 2009). Ao realizar uma revisão de literatura sobre os óleos essenciais do gênero Hyptis, McNeil, Facey e Porter (2011), encontraram algumas variações na composição química de mesmas espécies do gênero Hyptis, porém de locais distintos, e atribuíram essas variações às condições climáticas de cada local. O mesmo foi observado por Santos et al. (2018) em estudos realizados com duas espécies do gênero Hyptis. Sendo assim, de acordo Ehlert et al. (2013), ao trabalhar com plantas medicinais é necessário o conhecimento sobre vários métodos de plantio, manejo e pós-colheita visando estabelecer qual procedimento favorece maior concentração dos componentes de 
relevância ou, ainda, qual técnica possibilita a expressão de novos compostos. Obtendo essas informações é possível maior controle de qualidade e padronização na extração de óleos essenciais.

A temperatura de secagem é um fator pós-colheita que pode influenciar de forma direta no teor e qualidade do óleo essencial. Queiroz et al. (2018) ao estudarem a integridade de tricomas de alecrim-pimenta (Lippia origanoides), realizaram a secagem das folhas em quatro temperaturas diferentes de secagem em estufa $\left(40^{\circ} \mathrm{C}, 50^{\circ} \mathrm{C}, 60{ }^{\circ} \mathrm{C}, 70^{\circ} \mathrm{C}\right)$, utilizaram hidrodestilação como método de extração e cromatografia gasosa acoplada a espectrometria de massas para análise da composição química. Concluíram que a temperatura de secagem altera o teor e composição química do óleo essencial, sendo recomendado secar as folhas a uma temperatura de $40^{\circ} \mathrm{C}$ e possibilitando maior teor de óleo essencial e composto principal (timol) a ser extraído.

Diante da variedade de coeficientes de influência sobre o teor dos óleos essenciais, considerando as aplicações da fração volátil da espécie em estudo e a carência em pesquisas, o presente trabalho visa identificar quais condições de coleta e temperatura de secagem proporcionam maior teor de óleo essencial e possíveis variações na constituição química mediante a esses fatores.

\section{Metodologia}

\subsection{Coleta do material vegetal}

O município de Muzambinho está situado na região Sul de Minas Gerais, encontra-se a $21^{\circ} 20^{\prime} 47^{\prime}$ 'Sul de latitude e $46^{\circ} 32^{\prime}$ '04" de longitude Oeste de Greenwich, a uma altitude de 1033 metros. O material vegetal foi coletado no dia 13 de setembro de 2018 e, de acordo com os dados climatológicos, no IFSULDEMINAS, Campus Muzambinho no referido mês a temperatura média foi de $19,6{ }^{\circ} \mathrm{C}$ e o índice pluviométrico na região Sul mineira foi de $84,6 \mathrm{~mm} \mathrm{mês}{ }^{-1}$ (Aparecido \& Souza, 2018). O material vegetal para a pesquisa foi coletado a partir de plantas matrizes do genótipo roxo, que se encontram no Setor de Jardinagem do IFSULDEMINAS Campus Muzambinho, Muzambinho-MG, por volta das 7 horas da manhã. A exsicata da espécie está depositada no herbário da Universidade Federal de Lavras, sob código ESAL 13955. Foram utilizadas as inflorescências, visto que Botrel e colaboradores (2009) identificaram que essa parte da espécie em estudo apresenta maior teor de óleo essencial que outros órgãos da planta (folhas e caule). Visando responder aos objetivos da pesquisa, foram colhidas florescências de duas posições diferentes da planta matriz: apical e mediana. O material foi fragmentado manualmente e higienizado em água corrente.

\subsection{Secagem e extração}

O trabalho procedeu através de delineamento inteiramente casualizado (DIC), em esquema fatorial, contendo 4 tratamentos ( 2 posições de coleta das inflorescências submetidos a 2 temperaturas de secagem), em duplicata, totalizando 8 parcelas. O material vegetal foi pesado antes de ser submetido à secagem. A região apical resultou em 479,537 $\mathrm{g}$ de massa fresca e a região mediana $347,244 \mathrm{~g}$. A massa de cada região foi dividida para os dois tratamentos, $40{ }^{\circ} \mathrm{C}$ e $60{ }^{\circ} \mathrm{C}$. O material vegetal foi colocado para secagem em estufa de circulação de ar por um período de 48 horas. Após a secagem, o material vegetal de cada tratamento foi dividido novamente para análise do teor em duplicata. Dessa forma, a matéria seca final da região apical à $40^{\circ} \mathrm{C}$ foi $52,8935 \mathrm{~g}$ para cada parcela, para a mesma posição a $60^{\circ} \mathrm{C}$ foi obtida massa final de $51,1605 \mathrm{~g}$ para ambas as parcelas. Para a posição mediana a $40{ }^{\circ} \mathrm{C}$ foi obtido 43,9105 g para cada parcela e para essa mesma posição à $60{ }^{\circ} \mathrm{C}$ obteve-se 44,7030 g para ambas as parcelas. Após a conclusão do processo de secagem e aferição da massa extraiu-se o óleo essencial de cada uma das parcelas.

A extração do óleo essencial foi realizada no Laboratório de Biotecnologia e Cultura de Tecidos Vegetais do IFSULDEMINAS, Campus Muzambinho, Muzambinho-MG, pelo método de arraste a vapor através do aparelho mini 
destilador Linax ${ }^{\circledR}$, por um período de uma hora e trinta minutos após a fervura. A separação do hidrolato se deu através de partição líquido-líquido por meio de um funil de separação, efetuando-se três lavagens da fração volátil com diclorometano. As lavagens foram efetuadas com o volume médio de $10 \mathrm{~mL}$ do solvente agindo por quinze minutos. Os recipientes contendo o material foram completamente embrulhados em papel alumínio e não receberam tampa. Para que houvesse evaporação do diclorometano, o papel alumínio da área superficial dos recipientes recebeu pequenos furos realizados com lâmina. Durante todo o processo de evaporação, os frascos ficaram armazenados em Capela de Exaustão de Gases e foram pesados ao decorrer dos dias até que houvesse estabilidade no peso. Diante da massa obtida, determinou-se o teor percentual do óleo essencial pela fórmula: $\mathrm{T} \%$ = Massa do óleo (g) / X g x 100. Os dados do teor de óleo essencial foram determinados em \%, em seguida foram submetidos à análise de variância, empregando o software estatístico Sisvar (Ferreira, 2011). As médias foram aplicadas ao teste de Scott-Knott, com p $<0,10$. Após a conclusão de todas as etapas e obtido o peso final de óleo essencial, os frascos foram tampados e armazenados em geladeira, a $\pm 7{ }^{\circ} \mathrm{C}$, e posteriormente foram encaminhados à UNIFAL (Universidade Federal de Alfenas) para realização da análise química do material.

\subsection{Análise Química}

As análises químicas foram realizadas no Laboratório de Análise de Toxicantes e Fármacos da Universidade Federal de Alfenas (UNIFAL), Alfenas MG, por meio de cromatografia gasosa acoplada a espectrometria de massas. Esse tipo de análise possibilita grande quantidade de informações estruturais e assegura maior exatidão na identificação. As análises foram realizadas em um equipamento de cromatografia gasosa, GC MS-QP2010 Plus®, acoplado a um Espectrômetro de Massas (triplo quadrupolo), com Auto injetor AOC-20i. As condições operacionais utilizadas foram: Coluna analítica, modelo Macherey-Nagel (30 m de comprimento, 0,25 mm de diâmetro interno e 0,25 $\mu \mathrm{m}$ de espessura do filme), com fluxo de $1 \mathrm{~mL}$ $\min ^{-1}$ de hélio como gás de arraste; aquecimento com temperatura programada $\left(60^{\circ} \mathrm{C}\right.$ com um gradiente de $3{ }^{\circ} \mathrm{C} \min ^{-1}$ até $230^{\circ} \mathrm{C}$ e, em seguida, com um gradiente de $10^{\circ} \mathrm{C} \min ^{-1}$ até $270{ }^{\circ} \mathrm{C}$, mantendo-se uma isoterma de $7 \mathrm{~min}$, com um tempo total de corrida de $70 \mathrm{~min}$ ). A energia de ionização do detector foi de $70 \mathrm{eV}$, a 21 amostra preparada foi diluída em 500 microlitros de diclorometano para extração do composto, sob agitação constante em uma mesa de agitação por 4 horas, injeção de um microlitro no cromatógrafo. As temperaturas do injetor e do detector permaneceram em 220 e $240{ }^{\circ} \mathrm{C}$, respectivamente. A análise foi realizada no modo varredura, a uma velocidade de $2000 \mathrm{scan} / \mathrm{s}$, com um intervalo de aquisição de massas de 40-400 $\mathrm{m} / \mathrm{z}$. A análise quantitativa foi alcançada através de integração do cromatograma total de íons (TIC). O reconhecimento dos compostos se deu por meio dos espectros de massas com banco de dados da biblioteca NIST/EPA/NIH (INSTITUTE OF STANDARDS AND TECNOLOGY-NIST 2008), juntamente da comparação dos espectros de massas e índices de retenção (IR) com os da literatura (Adams, 2017) e coinjeção com padrões autênticos. Os IR foram calculados através da coinjeção com uma mistura de hidrocarbonetos, C10-C27, e com aplicação da Equação de Van Dool e Kratz.

\section{Resultados e Discussão}

As frações voláteis extraídas apresentaram tonalidade amarelo leve e aroma acentuado. Após aplicação do teste estatístico Scott-Knott, foi possível observar diferenças significativas no teor do óleo essencial de H. marrubioides para a posição apical da planta em relação à temperatura de secagem, sendo superior a $60^{\circ} \mathrm{C}(0,0353 \%)$. O mesmo não foi observado para a posição mediana da planta (Figura 1). 
Figura 1. Teor de óleo essencial de Hyptis marrubioides sob variações de temperatura de secagem $\left(40^{\circ} \mathrm{C}\right.$ e $\left.60^{\circ} \mathrm{C}\right)$ e posição de coletadas inflorescências na planta matriz. IFSULDEMINAS - Campus Muzambinho, Muzambinho, MG, 2019.

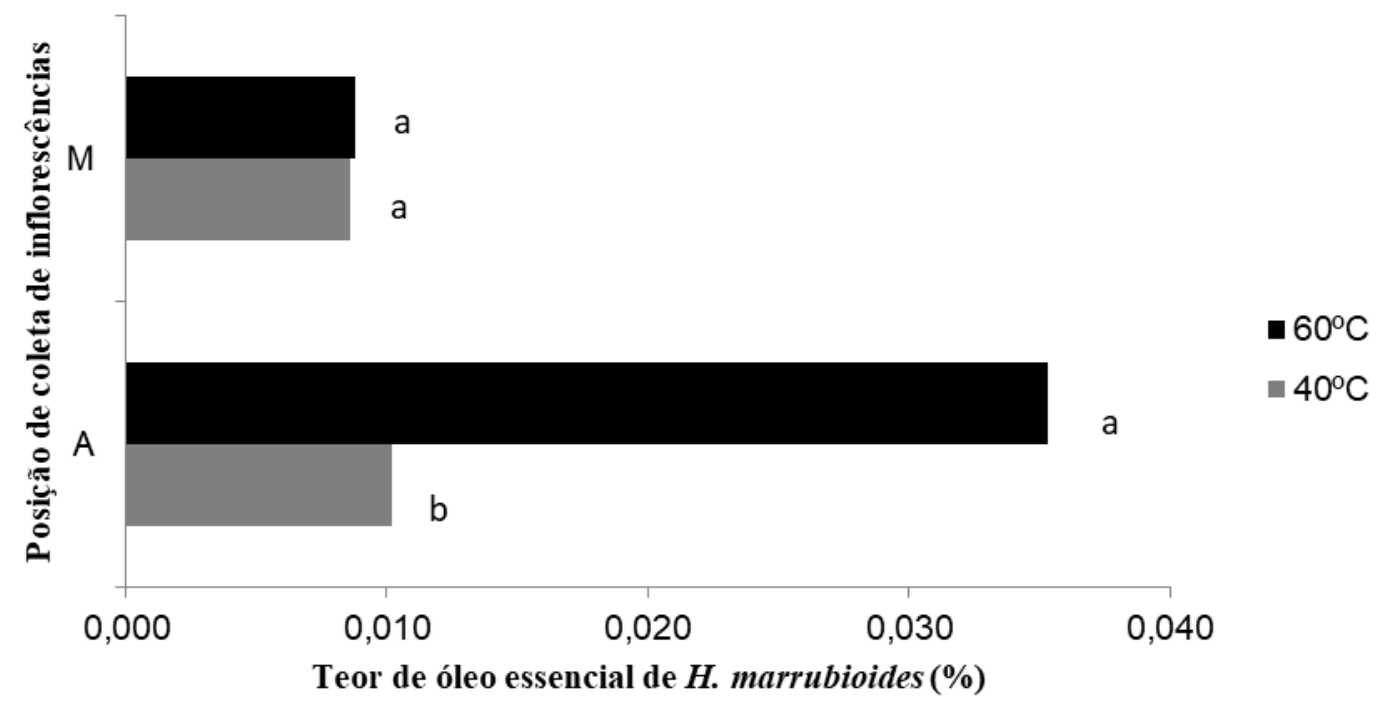

A= Apical; M= Mediana. Fonte: Dados da Pesquisa.

Ao estudar Cordia verbenacea DC, Souza e colaboradores (2011) verificaram maior teor de óleo essencial na posição mediana da planta em relação à posição apical, resultados diferentes dos aqui encontrados. Possivelmente essa diferença se deve ao fato de se tratarem de espécies diferentes.

A secagem é um procedimento importante para conservação do material vegetal. As atividades de microrganismos sobre a planta colaboram para com as modificações no teor dos metabólitos (Santana et al., 2014). Sendo assim, a secagem é uma forma de minimizar esse problema, uma vez que evita o crescimento microbiano. Melo, Radunz e Melo (2004), ao realizarem uma revisão de literatura sobre a influência do processo de secagem na qualidade de plantas medicinais, verificaram que as temperaturas entre $50^{\circ} \mathrm{C}$ e $60^{\circ} \mathrm{C}$ são aplicáveis para secagem de muitas plantas medicinais, independente do processo adotado, quebrando o padrão de $40{ }^{\circ} \mathrm{C}$ como temperatura máxima para secagem de espécies fitoterápicas. Sendo assim, observa-se que a temperatura ideal de secagem varia de acordo com a espécie a ser estudada.

As análises químicas foram realizadas em (CG-EM) e identificaram quarenta compostos para a posição apical da $H$. marrubioides, tanto quando submetida à $40^{\circ} \mathrm{C}$ (Figura 2), quanto quando submetida à $60^{\circ} \mathrm{C}$ (Figura 3), e cinquenta compostos para a posição mediana da planta, também para ambas as temperaturas de secagem (Figuras 4 e 5), de acordo com a biblioteca NIST 2008 (National Institute of Standards and Technology). 
Figura 2. Picos cromatográficos da inflorescência coletada da região apical de Hyptis marrubioides à $40^{\circ} \mathrm{C}$.

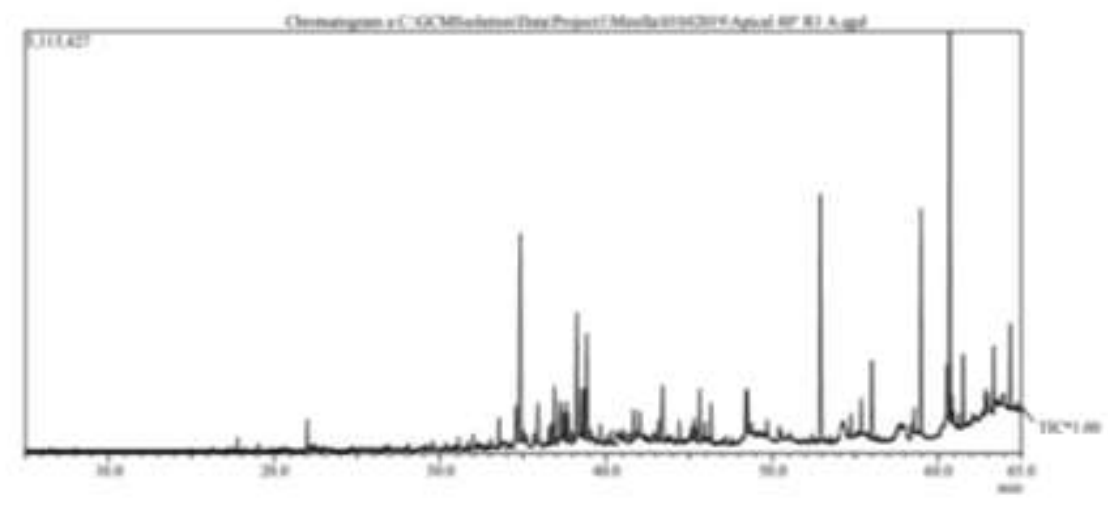

Fonte: Dados da pesquisa.

Figura 3. Picos cromatográficos da inflorescência coletada da região apical de Hyptis marrubioides a $60^{\circ} \mathrm{C}$.

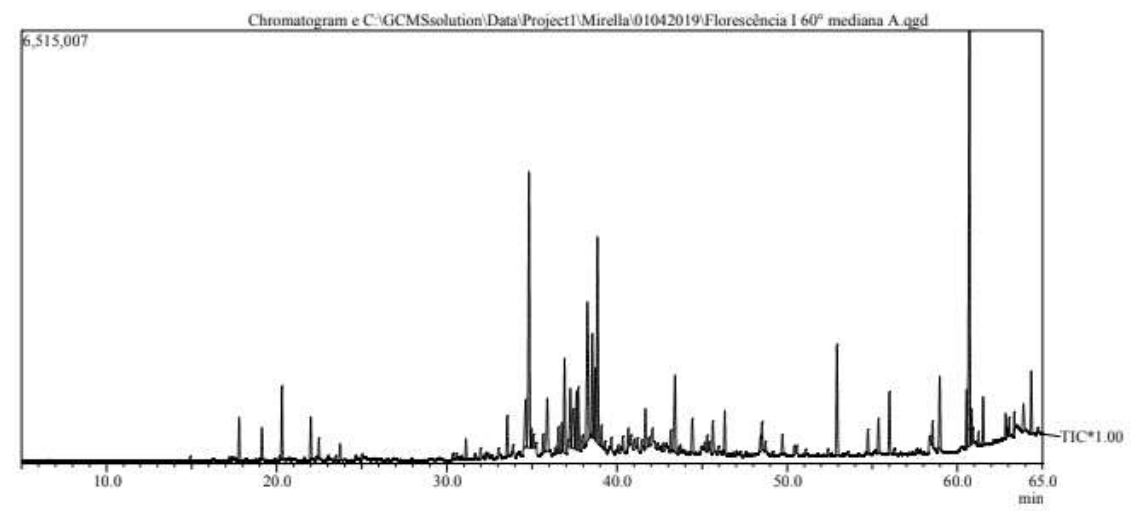

Fonte: Dados da pesquisa.

Figura 4. Picos cromatográficos da inflorescência coletada da região mediana de Hyptis marrubioides a $40^{\circ} \mathrm{C}$.

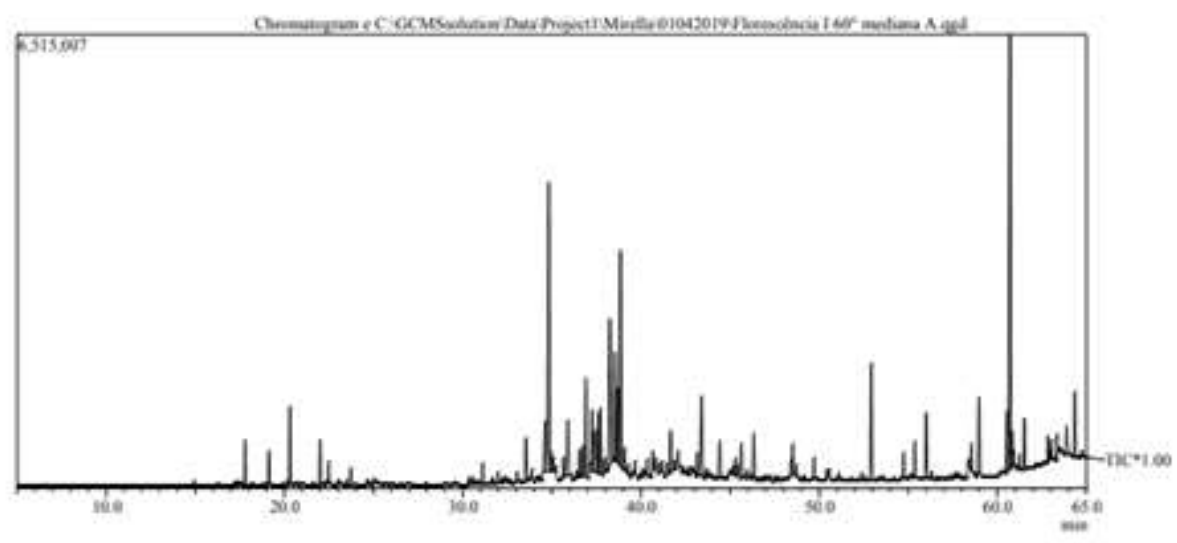

Fonte: Dados da pesquisa. 
Research, Society and Development, v. 10, n. 13, e584101321532, 2021

(CC BY 4.0) | ISSN 2525-3409 | DOI: http://dx.doi.org/10.33448/rsd-v10i13.21532

Figura 5. Picos cromatográficos da inflorescência coletada na região mediana de Hyptis marrubioides a $60^{\circ} \mathrm{C}$.

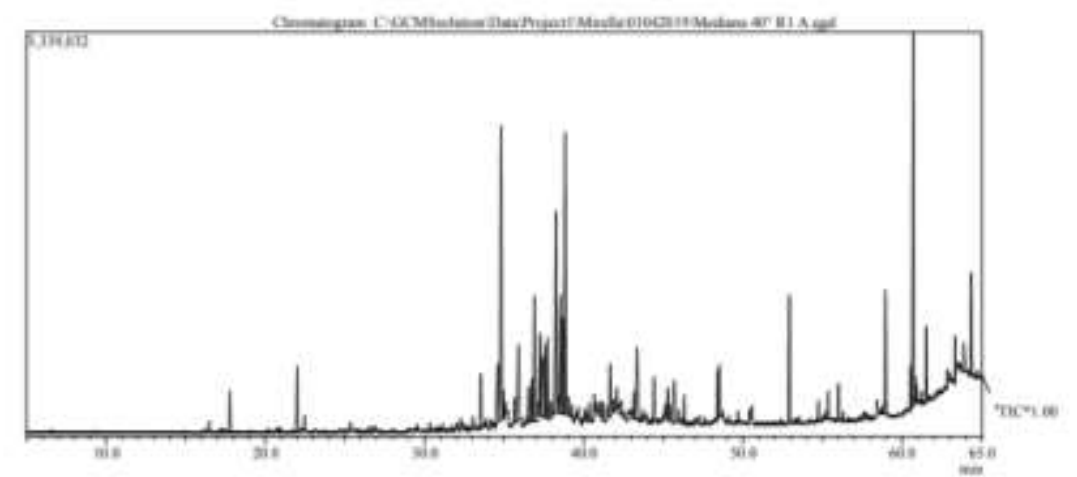

Fonte: Dados da pesquisa.

Ao comparar os resultados dos cromatogramas com literatura (Adams, 2017), foram identificados 37 compostos, listados no Quadro 1: 
Research, Society and Development, v. 10, n. 13, e584101321532, 2021

(CC BY 4.0) | ISSN 2525-3409 | DOI: http://dx.doi.org/10.33448/rsd-v10i13.21532

Quadro 1. Compostos químicos das inflorescências de Hyptis marrubioides identificados através de análises em CG-EM, comparados com a literatura (Adams, 2017).

\begin{tabular}{|c|c|c|c|c|c|c|}
\hline & & & \multicolumn{2}{|c|}{ APICAL } & \multicolumn{2}{|c|}{ MEDIANA } \\
\hline & & & $40^{\circ} \mathrm{C}$ & $60^{\circ} \mathrm{C}$ & $40^{\circ} \mathrm{C}$ & $60^{\circ} \mathrm{C}$ \\
\hline IK & CONSTIIUNTES & CLASSE & \multicolumn{4}{|c|}{ ÁREA \% } \\
\hline 1229 & Nerol & _- & 0 & 0 & 0 & 0,77 \\
\hline 1252 & Geraniol & - & 0 & 0 & 0 & 1,89 \\
\hline 1290 & Thymol & M.O & 0 & 1,63 & 0 & 0 \\
\hline 1290 & p-Cymen-7-ol & M.O & 0,86 & 1,61 & 1,49 & 1,17 \\
\hline 1299 & Carvacrol & M.O & 0 & 0 & 0 & 0,52 \\
\hline 1578 & Spathulenol & S.O & 1,63 & 0 & 0 & 0 \\
\hline 1583 & Caryophyllene oxide & S.O & 7,9 & 9,93 & 8,11 & 9,23 \\
\hline 1590 & $\beta$-Copaen-4- $\alpha-01$ & S.O & 0 & 0,69 & 0,64 & 0,51 \\
\hline 1608 & $\beta$-A tlantol & S.O & 1,68 & 0 & 2,36 & 2,18 \\
\hline \multirow[t]{2}{*}{1619} & 1,10-di-epi-Cubenol & S.O & 0 & 1,29 & 0,94 & 0 \\
\hline & Caryophylla-4(12),8(13)-dien- $5 \alpha-01$ & S.O & 0,76 & 1,54 & 1,26 & 1,03 \\
\hline 1640 & Caryophylla $-4(12), 8(13)$-dien $-5 \beta-01$ & S.O & 2,14 & 4,33 & 3,26 & 3,01 \\
\hline 1646 & Cubenol & S.O & 1,35 & 2,79 & 2,33 & 2,08 \\
\hline 1649 & (Z)-Methyl jasmonate & _- & 1,55 & 3,06 & 2,69 & 2,13 \\
\hline 1654 & $\alpha$-cadinol & S.O & 0 & 0 & 2,89 & 0 \\
\hline 1660 & Gymnomitrol & _- & 2,16 & 3,71 & 0 & 0 \\
\hline 1669 & 14-hydroxy-9-epi-(E)-Caryophyllene & S.H & 0 & 3,34 & 2,37 & 2,25 \\
\hline 1677 & Mustakone & S.O & 1,67 & 3,89 & 3,08 & 3,2 \\
\hline 1686 & Germacra-4(15),5,10(14)-trien-1- $\alpha-01$ & S.O & 5,34 & 9,67 & 8,12 & 7,31 \\
\hline 1699 & trans-Calamenen-10-01 & S.O & 1,17 & 0 & 0 & 0 \\
\hline 1706 & 14-hydroxy-4,5-dihydro-caryophyllene & S.H & 4,4 & 0 & 0,48 & 0 \\
\hline 1714 & Longifolol & _- & 0 & 1 & 0 & 0 \\
\hline 1760 & Benzyl benzoate & - & 1,26 & 0 & 0 & 0 \\
\hline 1780 & 14-hydroxy-a-Muurolene & 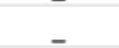 & 4,4 & 0 & 0 & 0 \\
\hline 1807 & 2-ethylhexyl-Salicylate & S.O & 0,71 & 0,82 & 0,64 & 0,61 \\
\hline 1908 & Diisobutyl phthalate & - & 0,81 & 0,72 & 0,83 & 0,48 \\
\hline 1968 & Palmitic acid & _- & 1,52 & 0 & 0 & 0 \\
\hline 2037 & Dibutyl Phthalate & 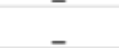 & 1,52 & 0 & 0 & 0 \\
\hline 2037 & n-Butyl phthalate & - & 0 & 0 & 1,49 & 0,88 \\
\hline 2021 & Palmitamide & 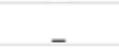 & 1,29 & 0 & 0,68 & 1,09 \\
\hline 2162 & Mono(2-ethylhexyl) phthalate & - & 2,45 & 2,3 & 2,04 & 1,57 \\
\hline 2228 & Oleamide & - & 0,8 & 0 & 9,08 & 13,17 \\
\hline 2228 & (Z)-9-Octadecenamide & - & 13,77 & 6,51 & 0 & 0 \\
\hline 2414 & Bis (2-ethylhexyl) adipate & - & 2,08 & 1,64 & 1,45 & 1,16 \\
\hline 2475 & Undecyl laurate & - & 0,6 & 0 & 0 & 0,54 \\
\hline 2546 & 2,3-Bis(acetyloxy)propyl myristate & - & 0 & 0 & 0 & 0,47 \\
\hline \multirow[t]{6}{*}{2902} & Bis (7-methylocty1) phthalate & _- & 0 & 0 & 2,12 & 0 \\
\hline & $\mathbb{K}=$ Indice de Kovats (literatura) & & & & & \\
\hline & $\mathrm{M} . \mathrm{O}=$ monoterpenos oxigenados & & & & & \\
\hline & $\mathrm{SH}=$ sesquiterpenos hidrogenados & & & & & \\
\hline & $\mathrm{S} . \mathrm{O}=$ sesquiterpenos oxigenados & & & & & \\
\hline & Traço $=$ não clas sificados & & & & & \\
\hline & & & & & & \\
\hline
\end{tabular}

Fonte: Dados da pesquisa.

Ao explorar as análises químicas observam-se diferenças quanto às concentrações relativas (\%) em relação aos compostos encontrados mediante a posição de coleta da inflorescência e temperatura de secagem. É possível ainda constatar que alguns compostos só foram encontrados mediantes determinadas temperaturas e/ou posições. 
No presente trabalho pode-se observar a presença de óxido de cariofileno como composto majoritário, presente em ambas as partes estudadas, nas seguintes concentrações: 7,9\% Apical $40{ }^{\circ} \mathrm{C} ; 9,93 \%$ Apical $60{ }^{\circ} \mathrm{C} ; 8,11 \%$ Mediana $40{ }^{\circ} \mathrm{C}$; 9,23\% Mediana $60^{\circ} \mathrm{C}$. Esse composto é um sesquiterpeno, maior grupo de metabólitos secundários. De acordo com Chavan, Wakte e Shinde (2010), o composto Óxido de Cariofileno apresenta propriedades analgésicas e anti-inflamatórias. Esse mesmo composto foi encontrado de forma majoritária no trabalho de Sales e colaboradores (2007), quando estudaram a variação química no óleo essencial de H. marrubioides de lugares distintos do Cerrado Brasileiro, em uma concentração de 5,8- 15,4\%. O trabalho em questão extraiu o óleo a partir de folhas e obteve também como compostos majoritários cariofila-4(14),8(15)-

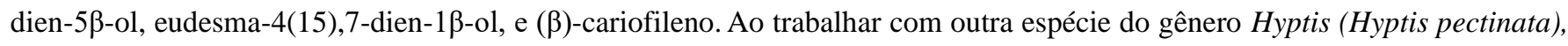
sob variações de temperatura de secagem e velocidade do ar, Branquinho et al. (2018) também constataram óxido de cariofileno como composto majoritário, em maior concentração na temperatura de $55{ }^{\circ} \mathrm{C}$, sob variações de 42 a $53 \%$. Botrel e colaboradores (2010), ao estudarem o teor e composição química de $H$. marrubioides cultivada em campo e em casa de vegetação também verificaram a presença desse composto, em uma concentração de 7,36\% e 8,03\% respectivamente.

Ao comparar as análises químicas do presente trabalho com as análises químicas de H. marrubioides realizadas por Sales et al. (2007) e Botrel et al. (2010), observa-se variação entre os constituintes encontrados. Masetto et al. (2011) também verificaram diferenças no teor e composição química estudando Lavandula dentata L. relacionadas ao estádio de desenvolvimento floral e época de colheita, a qual constatou quantidade superior de hidrolato no estádio em botão, independente da época de colheita. Dessa forma, pode-se sugerir que a idade da planta ocasionou as variações entre os compostos encontrados, uma vez que o material vegetal da pesquisa de Sales et al. (2007) e Botrel et al. (2010) eram oriundos de plantas jovens e do presente estudo encontrava-se em florescimento caminhando para senescência.

\section{Conclusão}

Conclui-se que a posição apical das inflorescências de Hyptis marrubioides apresenta maior teor e rendimento de óleo essencial, especialmente quando submetidas à temperatura de secagem de $60^{\circ} \mathrm{C}$. As variações de posição e temperatura de secagem influenciam quantitativamente e qualitativamente a análise química do óleo essencial. O composto majoritário encontrado na inflorescência de Hyptis marrubioides foi o Óxido de Cariofileno, identificado em ambas as posições de coleta e temperaturas de secagem, verificado em maior quantidade na temperatura de secagem de $60^{\circ} \mathrm{C}$.

\section{Referências}

Adams, R. P. (2017). Identification of essential oil components by gas chromatography/quadrupole mass spectroscopy. AlluredPublishing Corporation.

Aparecido, L. E. O., \& Souza, P. S. (2018). Boletim climático do IFSULDEMINAS.

Batista, J. A.; Botrel, P. P.; \& Figueiredo, F. C. (2015). Efeito do extrato de tiririca e bioestimulante no enraizamento de estacas de Hyptis marrubioides Epl. Pouso Alegre. Revista Agrogeoambiental, 7 (2), 91-99.

Branquinho, N. A. A. et al. (2018). Influence of Drying in Hyptis pectinata Essential Oil. Journal of Agricultural Science, 10 (4), $96-103$.

Botrel, P. P. et al. (2009). Teor e composição química do óleo essencial de Hyptis marrubioides Epling (Lamiaceae) em diferentes genótipos. Revista Brasileira de Plantas Medicinais, 11 (2), 164-169.

BotreL, P. P. et al. (2010) Variações no teor e na composição volátil de Hyptis marrubioides EPL: cultivada no campo e em casa de vegetação. Química Nova, $33(1), 33-37$.

Dantas, L. A. et al. (2021) Spectral quality as an eliciting agent in the production of phenolic compounds in the callus of Hyptis marrubioides Epling. Research, Society and Development, $10(9), 1-17$.

Ehlert, P. A. D., et al. (2013) Influência do horário de colheita sobre o rendimento e composição do óleo essencial de erva-cidreira brasileira Lippia alba (Mill.) N. E. Br. Revista Brasileira de Plantas Medicinais, 15 (1), 72-77.

Ferreira, D. F. (2011) Sisvar: a computer statistical analysis system. Ciência e agrotecnologia, 35(6), 1039-1042. 
Research, Society and Development, v. 10, n. 13, e584101321532, 2021

(CC BY 4.0) | ISSN 2525-3409 | DOI: http://dx.doi.org/10.33448/rsd-v10i13.21532

Harley, R. et al. (2015). Lamiaceae in Lista de Espécies da Flora do Brasil. Jardim Botânico do Rio de Janeiro. <http://floradobrasil.jbrj.gov.br/jabot/floradobrasil/FB8227>.

Magalhães, V.; Rios, R., \& Dias, A. (2020). Comparative Study on the Inhibition of Acetylcholinesterase Activity by Hyptis marrubioides, Hyptis pectinata and Hyptis suaveolens Methanolic Extracts. Proceeding, 4(10), 1-6.

Masetto, M. A. M., et al. (2011). Teor e composição do óleo essencial de inflorescências e folhas de Lavandula dentata L. em diferentes estádios de desenvolvimento floral e épocas de colheita. Revista Brasileira Plantas Medicinais, 13(4), 413-421.

Mcneil, M., Facey, P., \& Porter, R. (2011). Essential Oils from the Hyptis genus - A Review (1909-2009). Natural Product Communications, 6(11), 17751796.

Mello, M. B., et.al. Atividade inseticida do óleo essencial de Hyptis marrubioides no controle de Zabrotes subfasciatus (Coleoptera, Chrysomelidae, Bruchinae). Revista Agrogeoambiental. 6 (1),79-86.

Melo, E. C; Randuz, L. L., \& Melo, R. C. A. (2004). Influência do processo de secagem na qualidade de plantas medicinais - Revisão. Engenharia na Agricultura, 12 (4), 307-315.

Morais, L. A. S. (2009). Influência dos fatores abióticos na composição química dos óleos essenciais. Horticultura Brasileira, 27 (2).

Povh, J. A; Santos, F. B; Silva, K. R. (2012). Teor de fenóis totais e flavonóides em quatro espécies do gênero Hyptis Jacq. Ocorrentes no cerrado stricto sensu. Brazilian Geographical Journal: Geosciences and Humanities research medium, 3 (2), 520-528.

Queiroz, G. A. et al. (2018). A temperatura de secagem altera a integridade dos tricomas, o conteúdo químico e a composição do óleo essencial de alecrimpimenta. Ciencia Rural, Santa Maria, 48 (11), 1-8.

Rodrigues, M. A. et al. (2019) Cytokinins in the in vitro multiplication and analysis of the volatile fraction of Hyptis marrubioides. Revista Ciência Agronômica, 50(1), 90-99.

Sales, F. J. et al. (2007). Composition and Chemical Variability in the Essential Oil of Hyptis marrubioides Epl. Journal of Essential Oil Research,19 (1), $.553-556$.

Santana, A. C. M et al. (2014) Rupture of glandular trichomes in Ocimum gratissimum leaves influences the content of essential oil during the drying method. Revista Brasileira de Farmacognosia, 24, 524-530.

Santos, P. K. et al. (2018). Biological activity of Hyptis Jacq. (Lamiaceae) is determined by the environment. Industrial Crops and Products, 112 , 705-715.

Silva, A. C. et.al. (2014). Óleos essenciais de Hyptis marrubioides, Aloysia gratissima e Cordia verbenacea reduz o progresso da ferrugem asiática da soja. Acta Scientiarum. Agronomy, 36 (2), 159-166.

Souza, V. C., \& LorenzI, H. (2008). Botânica Sistemática. (2a ed.), Instituto Plantarum de Estudos da Flora Ltda.

Souza, M. F., et al. (2011). Influência do horário de coleta, orientação geográfica e dossel na produção de óleo essencial de Cordia verbenacea DC. Biotemas, 24 (1), 9-14. 